Acta Oeconomica, Vol. 64 (S1) pp. 81-110 (2014)

DOI: 10.1556/AOecon.64.2014.S1.3

\title{
GLOBAL, REGIONAL, AND COUNTRY-SPECIFIC COMPONENTS OF FINANCIAL MARKET INDICATORS*
}

\author{
Zalán KOCSIS
}

This paper studies the global, regional, and country-specific components of four key financial market indicators: sovereign CDS spreads, equity indices, exchange rates, and EMBI Global bond spreads. In all four markets, the results support the findings of the literature of a significant global component, but also point out the importance of regional correlations. Variance decompositions point to roughly a third of variance explained by both global and country-specific components in each of the four analysed financial markets, although there is considerable cross-country heterogeneity in this respect. The global factors of indicators are correlated across asset classes, but the market- and country-specific components of indicators are still significantly large to suggest diversification benefits of both multi-asset and multi-country portfolios. An application of the factor model suggests that the link between Central Eastern European and Euro zone periphery markets is stronger and more direct in the case of equity indices than in the case of sovereign CDS spreads.

Keywords: variance decomposition, factor analysis, Procrustes rotation, spillover, cross-country correlations, cross-asset correlations

JEL classification indices: C38, E44, G15

* I would like to thank Martín Saldias and Levente Pápa for being discussants of previous versions and the comments of the two anonymous referees of the current publication. I am also grateful for suggestions and support by colleagues at MNB, in particular, Csaba Csávás, Szilárd Erhart, Dániel Horváth, and Norbert M. Kiss, as well as for the comments of András Fülöp and Zoltán Reppa. The paper benefited from comments of experts of the national central

Zalán Kocsis, Economist at Magyar Nemzeti Bank (MNB, the central bank of Hungary). E-mail: kocsisz@mnb.hu 


\section{INTRODUCTION}

The identification of the source of shocks affecting financial markets has been a basic theme in the finance literature. It has been central to research aiming to explain the drivers of key indicators of various asset classes: risk premia in bond yields and foreign exchange rate movements, credit default swap spreads, and excess returns of equity prices.

Besides the descriptive academic interest, this field has had significant implications for both financial practitioners and policy-makers. For financial practitioners explaining the sources of asset price movements has been important from both a risk management and an asset management perspective. Knowledge of the sources of shocks allows inference on the magnitudes of potential price variations due to specific risk types, while identifying dependence between asset prices is important in portfolio allocation decisions. For policy-makers, the key implication is that observing adverse financial market movements necessitates different policy responses according to what the reasons behind those movements are.

This paper aims to extract and study the common and idiosyncratic components of four key financial market indicators: equity indices, CDS spreads, foreign exchange rates and hard-currency bond yield spreads. The results of the decomposition are used for assessing the relative importance of such components in various asset classes and countries, as well as for gauging the nature of Euro zone peripheral risk propagation towards Eastern European markets. By employing data on indicators of these four asset classes, a wide cross-section of countries, and a daily sample of the 2009-2012 period, the paper provides a more complete assessment of these indicators in the recent post-crisis era than other studies.

In terms of methodology, the paper belongs to the strand of the literature, which uses latent variable methods to identify common and idiosyncratic shocks within financial indicators. Latent variable techniques have the advantage of being more efficient in the statistical separation of common and idiosyncratic elements than the alternative class of methods, which instead chooses the explicit modelling of various shocks by incorporating relevant proxy variables into models. ${ }^{1}$ Unfortunately, the relative greater efficiency of latent variable techniques

banks meeting on "International Linkages" (November 2011), the ECB Workshop on "Financial Contagion" (March 2012), the Hungarian Economic Association Annual Conference (December 2011), and the Forecasting Financial Markets Conference (May 2012).

The views, analysis, and conclusions in this paper are those of the author and not necessarily those of other members of the MNB (the central bank of Hungary) staff or the executive board.

1 Typical examples of the latter method are the inclusion of the VIX index to proxy for global risk pricing and domestic fiscal variables to represent local drivers.

Acta Oeconomica 64 (2014) 
usually comes at the cost of losing the interpretation for common shocks, especially in the case when more than one factors account for common variance of indicators. For many finance applications, however, knowledge of the sources of co-movements is essential. One such area is the interpretation of cross-country and cross-asset spillovers of various financial market shocks, which has grown in importance since the recent financial crisis. The methodological novelty of this paper is the application of a statistical technique, factor analysis with Procrustes rotation, to financial time series, which has both the efficiency benefits of latent variable techniques and the advantage of identifying factors that are well-interpretable for practical applications. The method is appropriate in the case when there is already some a priori information about the factor structure of the data. It identifies factors which are statistically valid representations of the data, while also being closest to the prior in a Euclidean distance sense.

In the current context, the prior is based on the assumption that financial indicators are affected by shocks of global, regional, and country-specific origins. This is in line with how market participants, analysts, and policy-makers usually think of the effects of financial market events and there are both theoretical (e.g. Allen - Gale 2000; Corsetti et al. 2005) and empirical studies (e.g. Beirne et al. 2009; Dasgupta et al. 2010) underpinning the global and the regional propagation of shocks.

The extracted global, regional, and country-specific components of indicators are used in three applications. First, variance shares of factors are calculated for each asset class and country. This yields several practical implications. It points out which factors are mainly responsible for price fluctuations on various markets and hence, which factors deserve more attention on the part of financial market analysts. It also suggests how much manoeuvring room policy-makers have, given the assumption that they can primarily impact country-specific components of indicators. Regarding asset classes as a whole, variance shares hint at how important systemic risks are in general and, in turn, how significant the benefits of portfolio diversification may be.

Second, the factor analysis results can be used for the interpretation of daily changes of any indicator by calculating the daily contributions of global, regional, and country-specific shocks. Although the technique works on the statistical segmentation of correlations and hence is unable to provide a causational interpretation of financial market phenomena, the decomposition along with a general understanding of financial market events may greatly assist financial market analyses.

In the third application, the nature of bivariate correlations between financial indicators of Eastern European and Euro zone periphery countries are assessed. The technique applied here is useful for providing estimates on the correlation 
shares due to factors and is thus helpful in the interpretation of how direct or indirect the link between these countries has been. If the correlation is primarily determined by the global factor, then the link is more indirect than in the case when the correlation is determined by a regional factor.

The paper is structured in the following way. Section 2 presents the data and the methodology used. Section 3 describes general results, while Section 4 considers financial market applications. Conclusions are provided in Section 5.

\section{METHODOLOGY AND DATA SET}

\subsection{Methodological approach and the related literature}

Existing empirical literature has proceeded to identify common and idiosyncratic components in a number of ways. The two more generally used latent variable methods have been dynamic latent factor models (Diebold - Nerlove 1989; King et al. 1990; Dungey - Martin 2007) and static methods, such as principal components analysis (Collin - Dufresne et al. 2001; Kim et al. 2009). In terms of methodology, this paper is closest to those in the literature which choose a third latent variable method, static factor analysis (McGuire - Schrijvers 2003; Broto Perez-Quiros 2011; Kocsis - Nagy 2011).

As opposed to dynamic factor models, factor scores estimated by static techniques are linear combinations of the original series, and therefore exhibit the empirical properties of the underlying series (e.g. heavy tails, volatility clustering) without the need to explicitly include these in the model specification. This is an advantage in terms of reducing the chances of model misspecification, but of course a static model loses the explicit quantification of these characteristics of the data. Compared to principal components, static factor analysis assumes a data generating process that is more consistent with the theory of having systemic and idiosyncratic components in financial indicators, although in most applications the two methods produce very similar results.

The main problem of latent variable methods, as mentioned above, is that extracted common factors are usually hard to interpret. For most forecasting applications and for applications where only the common-idiosyncratic breakdown matters, this is not a problem. However, in other applications one is interested in the interpretation of the sources of commonality in the data set.

Within the realm of latent variable techniques, the economics and finance literature typically used block zero restrictions on factor loadings to identify factors. For example, in a macroeconomic context Kose et al. (2003) identify global, regional, and country factors of macroeconomic variables, while Dungey - Martin

Acta Oeconomica 64 (2014) 
(2007) identify global, market, and country factors of financial market indicators. In the case of Kose et al. (2003), regional groupings of series are assumed $a$ priori. Block zero factor restrictions in both of these studies rely on the assumption that a given indicator is driven only by their own regional/market/country factors apart from global and idiosyncratic shocks. Technically speaking, in these settings, loadings of other regions/markets/countries are restricted to zero, though Dungey - Martin (2007) extends the model to studying remaining bivariate co-movements between indicators. A recent study of Francis et al. (2012) relaxes the a priori clustering of series and provides a framework that endogenously determines regional groups. However, in this case as well, only one regional loading is allowed to differ from zero.

In contrast, this study does not exclude the impacts of other regions, although it does make a prior assumption that such loadings are zero. Nevertheless, if the data is so structured, then the posterior ${ }^{2}$ will deviate from this prior and other regions may as well have an impact on the indicator. On the one hand, this setup allows a more flexible segmentation of cross-country correlations, one that offers an insight into correlation channels. On the other hand, it also reduces the risk that an indicator is classified into a group that it does not belong to. Even though in many cases classification is unproblematic, sometimes there may be borderline cases.

The paper belongs to the relatively smaller group of studies which deals with cross-country co-movements using data of multiple asset classes (Forbes - Chinn 2003; Ehrmann et al. 2005; Dungey - Martin 2007; Longstaff et al. 2011). One advantage of this approach is that analysing several markets together may permit better founded general conclusions on indicators of a given country compared to studying a single asset market alone, since each market may have additional specificities. Second, these market-specific features may be interesting in their own right and may hint at different characteristics of various asset classes. Third, the general "global" components of various market indicators may be analysed to see the extent of co-movements between indicators, which may suggest diversification benefits of multi-asset portfolios.

I use the term "posterior" and "posterior solution" throughout the article referring to the results that follow from the information contained in both the prior and the used data set. This concept is similar to posterior probabilities of Bayesian analysis, but should not be confused with that since the methodology of arriving to the posterior from the prior (probabilities) and the (likelihood of the) data are different in the two cases. 


\subsection{Factor analysis with Procrustes rotation}

The following description mostly relies on Anderson - Rubin (1956) and Browne (2001).

Static factor analysis assumes that the data generating process of the standardised form, $Z_{\mathrm{i}}$, of each variable $X_{\mathrm{i}}$ (e.g. a financial indicator of country $i$ ), is represented by:

$$
\frac{X_{i}-\mu_{i}}{\sigma_{i}}=Z_{i}=\sum_{j=1}^{p} l_{i, j} \cdot F_{j}+\varepsilon_{i}
$$

where $l_{i, j}$ is the loading of country $i$ 's indicator on the $j$-th factor given $p$, the number of common factors. The time series $Z_{i}$ can therefore be thought of as a linear combination of the factor time series and an (uncorrelated) residual term, $\varepsilon_{i}$. In the case of orthogonal factors (which are used throughout this paper), the variance-covariance matrix of $Z$ is given by:

$$
\operatorname{cov}(Z)=E\left[\left(L F^{\prime}+\varepsilon^{\prime}\right)\left(L F^{\prime}+\varepsilon^{\prime}\right)^{\prime}\right]=L L^{\prime}+\Psi,
$$

where $\boldsymbol{L}$ is the $n \times p$ matrix of loadings for $n$ countries and $p$ factors, $\boldsymbol{F}$ is the $T x p$ matrix of factor time series with T observations, $\varepsilon$ is the $T \times n$ matrix of idiosyncratic shocks and $\Psi$ is an $n x n$ diagonal matrix of idiosyncratic variance components. For individual series this can be re-written as:

$$
1=\sigma^{2}\left(Z_{i}\right)=\sum_{i=1}^{p} l_{i, j}^{2}+\varepsilon_{i}^{2}
$$

Thus the (unit) variance of the (standardised) variable $Z_{i}$ is simply the sum of squared factor loadings and the variance of the idiosyncratic term. This formulation displays the variance share explained by each factor and the idiosyncratic component, which will be used in the application of Section 4.1.

A loading close to $+/-1$ on any factor yields a high $l^{2}$, indicating that the given factor is important in explaining the variance of the particular variable. Conversely, for those variables that do not co-move with any factors, the idiosyncratic term will dominate the information content and loadings will be close to zero.

Loadings can also be used to assess how two different indicators are correlated, i.e. which are the important channels of co-movements. For a given factor, $j$, the loadings $l_{i l, j}$ and $l_{i 2, j}$ represent correlations with the factor. Hence the product of the two loadings will be attributable to correlation between the two indicators through factor $j$. Summing loading products for all factors equals the total correlation between the two indicators if common factors truly capture all commonality. This property will be used in Section 4.1. 
Estimation of $\boldsymbol{L}$ and $\Psi$ requires knowledge of the number of factors to extract. While several methods are available for arriving at this quantity, these usually give a range of factor numbers to consider. In the current study, the criteria of scree plots, minimum eigenvalues, cumulated variance ratios, and the minimum average partial methods were taken into consideration (see the references listed at the beginning of the subsection).

Given the number of factors to extract, maximum likelihood estimation is commonly applied to arrive at the estimates of $\boldsymbol{L}$ and $\Psi$, which minimise the distance between the observed and estimated covariance matrix of $\boldsymbol{Z}$. The common idiosyncratic breakdown of total variance is determined by the method uniquely, but the loading matrix is not.

The Procrustes rotation overcomes this indeterminacy problem by minimising an objective function, $P(\boldsymbol{L})$, which is the sum of squared errors between the respective values in the (prior) target matrix and the (posterior) loading matrix:

$$
P(L)=\sum_{i=1}^{n} \sum_{j=1}^{p}\left(l_{i, j}-t_{i, j}\right)^{2} .
$$

The technique can be interpreted as the optimisation that finds the closest matrix to the target matrix in the Euclidean distance sense. The resulting solution has the same likelihood as a principal components-type of hierarchical factor solution, so that mathematically it is just as valid a representation of the common variance of the data set. In this paper orthogonal Procrustes rotation is used, thus the factors resulting from the rotation are uncorrelated with each other.

\subsection{Data set}

For the purposes of this study, those financial market time series were considered which were available for a relatively large number of countries on a daily frequency after 2009 and which represent quotes of relatively liquid instruments. Based on these criteria, time series of 5-year CDS spreads, stock market indices, foreign exchange rates versus the US dollar, and JP Morgan EMBI Global bond spreads were selected for 18-35 countries. (Table Al of the Appendix contains a detailed listing of the indicators of countries included for each asset class and their sources.)

The time sample is chosen to begin after the height of the financial crisis, in early 2009, in order to have a relatively homogenous data set. Homogeneity of the analysed data set is understood in the sense that the data is generated by the same process, i.e. that indicators in the period under review are determined by factors via the same (population) loading parameters. This is important in order to reduce 
the possibility of structural breaks, which have the effect of downward biasing the estimates of factor explained variances and upward biasing the share of idiosyncratic terms. Intuitively, if there were two subperiods, in both of which an indicator was perfectly explained by factors but the factor loadings changed, then the estimated loading on the full sample would deviate from the true subperiod loadings causing a spurious rise in the unexplained variance.

The period between 2009 and 2011 can be regarded as a thematically homogeneous period in financial markets: the period of the European sovereign debt crisis. On the other hand, the financial crisis of 2008-early 2009, and especially the era before the crisis, was characterised by significantly different correlation structures regarding cross-country co-movements (Kocsis - Nagy 2011). Another reason for choosing the time sample to begin in 2009 is the relative higher data quality in this period and the larger liquidity in several developed European country CDS markets. On the other hand, according to market participants, the November 2012 EU ban on naked short CDS positions may have impacted both CDS markets and indirectly FX bond markets increasingly from the middle of that year, which may have introduced a structural break around mid-2012. Our sample, however, ends at the beginning of 2012.

The exact beginning and ending dates are adjusted separately for each market so that the key indicator starting and end points are close in levels (see Table Al for the exact dates of estimation). The rationale behind this choice is that factor analysis operates on standardised variables and therefore neglects the constant term $\left(\mu_{\mathrm{i}}\right.$ in equation (1)), a result of long-term changes in the variable. From a practical viewpoint, choosing the sample in this way facilitates analysis as it avoids the constant, which is not attributable to any of the extracted factors. From the theoretical aspect, as well, the data generating process of first differences should not have a significant constant term since this would represent arbitrage opportunities (although smaller constants could be explained on the basis of risk neutral drift and there is a case against arbitrage-free relations in the context of the financial crisis).

\section{GENERAL FACTOR ANALYSIS RESULTS}

Bartlett tests and Kaiser-Meyer-Olkin measures demonstrate that the data sets of all asset classes are suitable for factor analysis (Table 1). The Bartlett tests indicate that correlations between variables are significant in all markets. The Kaiser-Meyer-Olkin measures are above 0.9 in all cases, which is considered ideal for factor analysis.

Preliminary analysis of the data establishes that a global component is relevant in the co-movement of indicators in all studied asset classes. Bivariate correla- 
Table 1

Adequacy measures for factor analysis

\begin{tabular}{lcccc}
\hline & CDS spreads & $\begin{array}{c}\text { Equity } \\
\text { indices }\end{array}$ & FX rates & $\begin{array}{c}\text { EMBI Global } \\
\text { spreads }\end{array}$ \\
\hline Bartlett-test p-value & $<0.00005$ & $<0.00005$ & $<0.00005$ & $<0.00005$ \\
KMO MSA & 0.963532 & 0.969635 & 0.949588 & 0.97285 \\
\hline
\end{tabular}

Notes: The Bartlett test has the null hypothesis that variance-covariances form an identity matrix (variables are independent). Its rejection indicates that correlations between variables are significant. The Kaiser-Meyer-Olkin measures of sampling adequacy (KMO MSA) are aggregates of the explained- to-unexplained ratios of variable variances.

tions are positive and significant between original time series and first principal components in the case of all data sets. Thus, when the first principal component of indicators in a given asset class increases, all indicators within that asset class are also expected to increase, which demonstrates a global phenomenon. Nevertheless, a global factor is not enough in itself to capture co-movements as evidenced by the four criteria that are used to assess the necessary factor numbers in each asset class (see Table A2). The criteria point to a range of 3-6 necessary factors in the case of CDS spreads; $3-4$ factors in case of equity indices; $2-4$ factors in case of FX rates; and 2-5 factors in case of EMBI Global (FX bond) spreads. Hence, multiple factors seem to be determining indicator co-movements.

To be able to interpret the factor structure of the data, the commonly used exploratory factor analysis technique, varimax rotation is carried out in the criteria-implied ranges for factor numbers. Varimax results ${ }^{3}$ highlight that regional geographical aspects are material in determining the factor structures of CDS spreads, equity indices, and EMBI Global bond spreads. ${ }^{4}$ Priors are created accordingly. To represent equal (1/3) prior variance weight for global, regional factors and the idiosyncratic term, the prior loadings of the target matrix are set to square root $1 / 3$. The regional structure is more obscure in the FX market, however. Therefore, in this case, a data-driven approach is followed, whereby regional membership is determined by the maximum loading in the varimax solution. (Prior classifications are presented in Table Al).

3 Varimax rotation results are not included here to save space, but are available from the author upon request.

4 The geographic classification is supported for CDS spreads by iTraxx SovX composite indices of Markit: (Latin America, Asia-Pacific, CEEMEA, and Western Europe) and composite equity indices of STOXX: All Europe + Africa, Asia + Asia Pacific, and Americas. 


\subsection{The global factors}

The existence of a global factor in all four asset classes analysed are confirmed above. Thus, the prior target matrices have been set up for the Procrustes rotation to include such a global factor. The Procrustes solutions (Tables A3.1-A3.4) for these asset classes (CDS, equity indices, FX rates, EMBI spreads) extract global factors with significant positive loadings for financial indicators of all countries as expected.

Table 2

Correlations between global factors

\begin{tabular}{lcccc}
\hline & CDS spreads & Equity indices & FX rates & EMBI spreads \\
\hline CDS spreads & 1.00 & -0.61 & 0.58 & 0.29 \\
Equity indices & & 1.00 & -0.63 & -0.29 \\
FX rates & & 1.00 & 0.31 \\
EMBI spreads & & & 1.00 \\
\hline
\end{tabular}

Notes: Pearson's correlation coefficient between factor score estimates of global factors of given indicators.

The Thurstone regression method is used to estimate the time series of latent factors, called the factor scores (see, e.g., Grice 2001). With the time series of global factors created, the correlations across markets can be examined. Table 2 reveals strong co-movements between three of the four markets, which is consistent with the "risk-on/risk-off dichotomy" of markets since the crisis. ${ }^{5}$ Correlation coefficients of roughly 60 percent in absolute value between the global components of CDS spreads, equity markets, and FX rates indicate that daily changes in any of these markets explain on average around 35 percent (i.e. the square of the correlation coefficient) of the movements in the other markets. Though this is a significant variance share, it also indicates a considerable role for remaining market-specificities across asset classes. Multi-asset portfolios may benefit from diversifying away significant market-specific idiosyncratic risk. Correlations with the EMBI Global spread global factor are significantly weaker.

Figure 1 displays the time series evolution of global factors in different markets (with the axis of equity indices reversed for ease of comparison). Since the onset in May 2009, various markets have displayed considerable volatility, with all asset classes exhibiting favourable tendencies in the second half of 2009, as the

5 The dichotomy refers to analysts' observation that trading days are either "risk on", when all asset markets experience a deterioration, or "risk off", when there is an across-the-board improvement of indicators. 


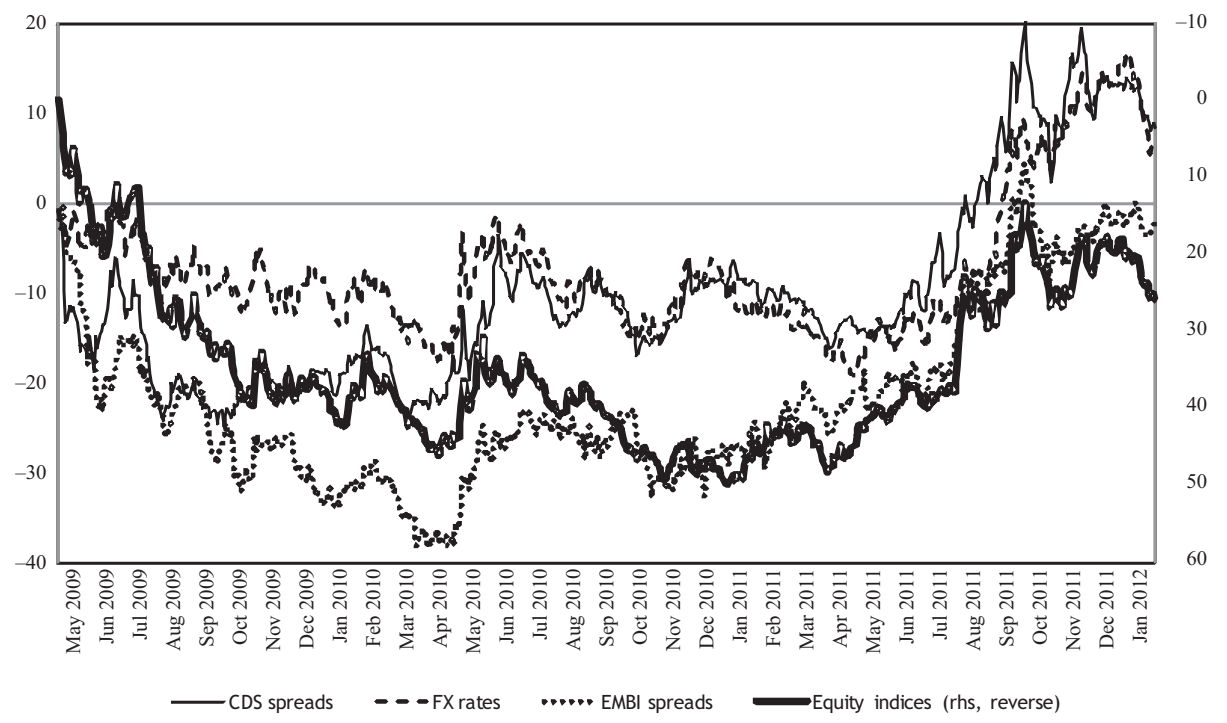

Figure 1. Cumulated changes of global factors (standard deviation units)

Notes: Time series of global factor score estimates are cumulated over the sample period. Daily values of the original time series (the changes of the depicted cumulated series) are measured in standard deviation units. Standard deviations of the factors are normed to 1 for the full sample by model design. Equity indices are graphed on a sign reversed right hand scale for ease of comparison with other asset class global factors.

threat of the financial crisis receded (credit spreads declined, currencies appreciated, stock indices increased). Early-mid 2010 exhibited turbulence due to Greece and the spread of the crisis to other peripheral countries, but this proved to be smaller in magnitude compared to the financial market stress that returned as of June 2011. At the end of the sample there has been a global improvement that seems to have affected stock markets relatively more than other asset markets.

\subsection{Regional factors}

The Procrustes solution on the CDS data set (35 countries) results in a global and four regional (EMEA, Asian, Latin American, and Euro zone) factors (Table A3.1). Most countries exhibit large positive loadings on their respective regional factors and close-to-zero loadings with other factors. Perhaps the Baltic countries can be mentioned to have weaker correlations with the EMEA region, while Russia, Turkey, and South Africa seem to have mild positive loadings on other factors. $^{6}$

6 Kocsis - Nagy (2011) provides a detailed analysis of the factor solutions for the CDS market for a similar estimation period and also for previous episodes. 
A relatively similar structure is found to be appropriate for the similarly sized (32-country) cross-section of equity indices (Table A3.2). The difference lies in having a combined European group of both Euro zone and emerging European countries. Therefore with equity indices, one global and three regional factors are the input for the Procrustes rotation. Of course, the inclusion of Euro zone and EMEA countries in a single group does not mean that equity indices in the two areas have moved on a similar scale. Rather, it only indicates that movement patterns were similar. In fact, there were large dissimilarities in the daily volatilities of European indices. Another difference compared with the CDS market is that Asian and American factors each include a developed country, Japan and the US, respectively.

FX rates led to a markedly different factor structure compared to other asset classes (Table A3.3). The data-driven varimax solution was used to form a rule-based prior for the Procrustes rotation (prior grouping were created according to maximum loadings of FX rates on factors resulting from a varimax rotation). This prior resulted in a posterior factor structure less on the geographic basis seen in other markets. The solution still separates an emerging Asian bloc (but separates it also from New Zealand and Australia), and one factor has high loadings on European currencies and highest on the EUR/USD exchange rate. Yet there is a hardly interpretable factor with currencies from various geographical regions (South Africa, Mexico, Australia, New Zealand, Canada).

JP Morgan's EMBI Global spread indices are constructed from yield spreads of USD-denominated liquid bonds of emerging markets. Therefore, this indicator-type excludes developed countries (hence there is no Euro zone factor). The factor structure is largely consistent with a geographic segmentation as Latin American countries are separated from the EMEA region (Table A3.4). However, the separation does not produce such clear factor structure as seen in either the CDS or the equity markets: several countries have relatively large loadings on the other region, while a few countries have low loadings on both regional factors.

\subsection{Robustness checks}

The posterior solution depends on the choice of the prior target matrix. Hence, on one hand it needs to be verified that the fit between the chosen prior and the solution is at least as good as the fit between other logical prior alternatives and their respective solutions. On the other hand, it needs to be checked that the fit between the prior and the posterior are not based on chance correlations. 
To proceed, first, alternative priors are chosen and their posteriors resulting from the Procrustes rotation are created. For CDS spreads, equities and EMBI Global spreads, where regional geographies are the basis of prior selection, the alternatives are set to be the data-driven varimax loading maximum method outlined above for FX rates and another data-driven prior that downweights the varimax loading matrix and augments it with a global factor. The latter prior choice is consistent with moving from the varimax setup, where a regional factor is expected to explain half of total variance, to a global plus regional setup, where a regional factor is expected to explain a third of total variance. In the case of FX rates, where the data-driven varimax loading maximum is chosen as the prior, the first alternative is the downweighted varimax method, while the second alternative is a geography-based segmentation.

For all factors of each asset class, there is a satisfactory fit between the chosen priors and the posteriors as evidenced by factor congruence statistics (see Table $A 4$, column 1). ${ }^{7}$ The high degree of fit demonstrates that the factors due to the Procrustes rotation can be interpreted the same way as the priors. Alternative priors also fit well to their respective Procrustes solutions (Table A4, columns 2 and 3), but compared with the degree of fit between chosen priors and posteriors, the difference is not significant, therefore it can be argued that the chosen priors are as good in terms of fit as the alternatives. In addition, congruence coefficients between posteriors also indicate a close fit in all asset classes (Table A4, last two columns), suggesting that different priors lead to similar solutions. Thus, the chosen priors seem to be at least as good a choice as logical alternative priors, and the particular choice does not seem to be material in influencing the results.

As a final point, it is checked that the fit between the prior and posterior is not spurious (McCrae et al. 1996). The congruence statistics between chosen priors and the Procrustes solutions are contrasted with similar statistics between random priors and their solutions. (Table A4, columns 4 and 5 report percentiles of the fit of priors and posteriors from random prior draws.) The statistics confirm that the chosen priors are significantly better in fitting the data than random prior draws are.

7 Factor congruence statistics measure the degree of fit between columns of loading matrices. A value of 1 indicates identity of factors. Lorenzo-Seva - ten Berge (2006) argue that values between $0.85-0.94$ can be considered to exhibit a satisfactory fit, whereas values above this range denote near equivalent factors. 


\section{APPLICATIONS}

\subsection{Variance decompositions}

Equation (3) is used to assess the explanatory power of different sources of shocks of a given indicator. According to (3), the variance share of factor $j$ is the squared loadings, $l_{i, j}^{2}$ of country $i$ on the factor. The residual variance of indicators not attributable to factors is the variance share of the idiosyncratic term.

Figure 2 summarises the results of variance decompositions. According to median values of variance shares of individual indicators, global and country-specific components of indicators explained roughly a third of total variances, with global factors contributing somewhat more and country-specific indicators contributing somewhat less than a third. The regional factors that the indicator was assigned to by the prior (referred to as own region) explained around a fourth of the total variance. Impacts of other regions have been small on the aggregate.

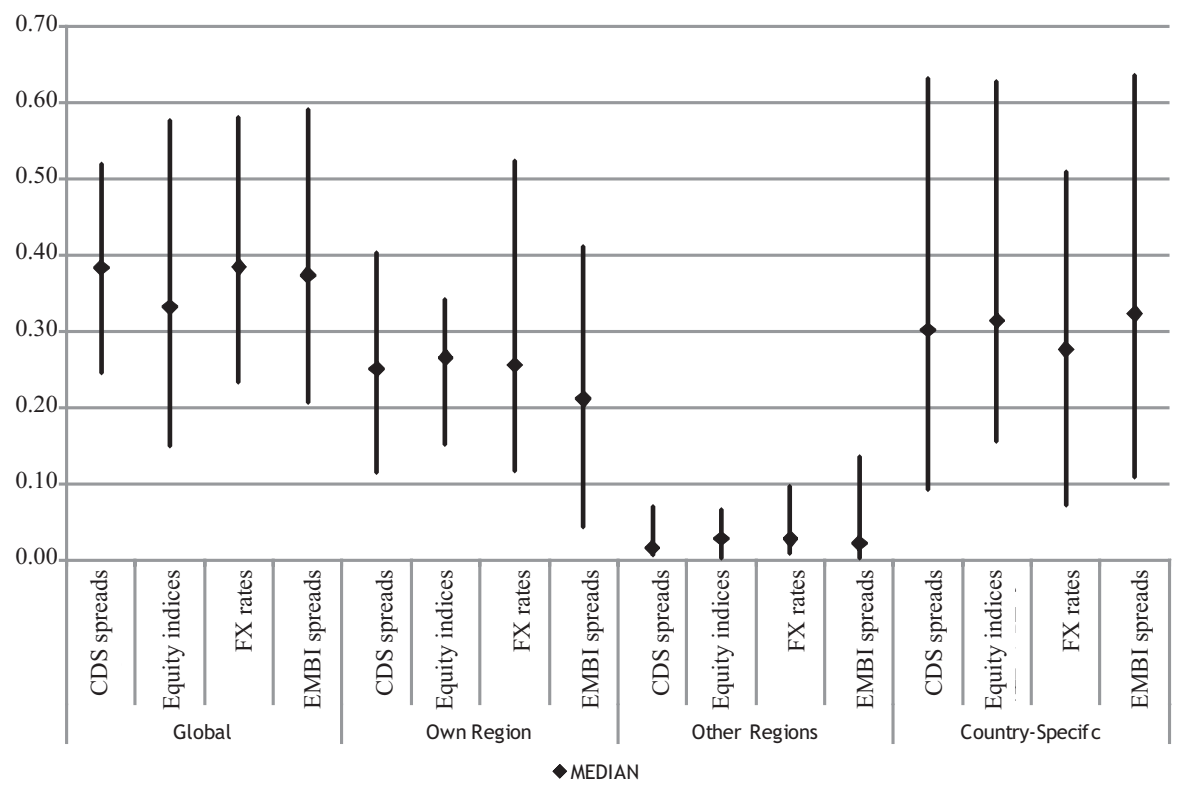

Figure 2. Shares of explained variances (medians and 25-75 percentile intervals)

Notes: Median and 25-75 percentile intervals of explained variance shares of components aggregated over country indicators for each asset class. For individual indicators, the explained variance shares of global factors are given by the squared loadings of the indicator on the global factor. Own regional variance shares are the squared loadings of the indicator on the regional factor that the indicator is assigned to by prior assumptions. Other regional variance shares, in turn, represent the sum of squared loadings of the indicator on other regional factors. The country-specific component share is the residual variance.

Acta Oeconomica 64 (2014) 
Median values of variance shares are nearly identical across asset classes, but individual indicators do display considerable dispersion from medians as evidenced by the 10-90 percentiles in Figure 2. (Table A5 reports variance decompositions for individual country indicators.) Even so, apparently in all asset classes all three components (global, regional, and country-specific) were significant in the daily changes of most indicators. Thus, besides global factors, regional factors were important as well. Country-specific idiosyncratic terms were also relevant in most indicators of each asset class, which confirms diversification benefits of multi-country portfolios and indicates that local factors and hence probably policy-making, as well, do have a potential to impact financial indicators. Yet, idiosyncratic terms should be assessed with caution because they may be a result of other country- and market-specific factors besides policy-making and because $10-90$ percentile ranges indicate large heterogeneity across individual country indicators.

\subsection{Monitoring the time series evolution of indicator components}

While the overall contributions of variances of various factors to indicators provide important general insights, for day-to-day market monitoring purposes the following application is more useful. Using the time series of factor score estimates, it is possible to approximate the contributions of various factors to daily changes of the indicators. To see this, equation (1) can be re-written in the following way:

$$
X_{i}=\mu_{i}+\sigma_{i}\left(\sum_{i=1}^{p} l_{i, j} F_{j}+\varepsilon_{i}\right)=\mu_{1}+\sigma_{i} \sum_{i=1}^{p} l_{i, j} F_{j}+\sigma_{i} \varepsilon_{i} .
$$

Factor contributions are given by $\sigma_{i} \sum_{i=1}^{p} l_{i, j} F_{j}$, while $\sigma_{i} \varepsilon_{i}$ denotes the idiosyncratic component. Since $X_{i}$ is in first difference terms, to visualise longer time series of the components, it is useful to plot the cumulated series instead of the changes themselves. Such an analysis can of course be conducted for any financial market indicators (of any country in the sample).

Moreover, the output of such monitoring tools for multiple indicators of a given country can be combined to strip indicators of market-specific noise. Then, one may arrive at more precise estimates of global, regional, and country-specific shocks affecting indicators on a daily basis. For example, extracting the first principal component of idiosyncratic terms of various market indicators (of the same country), a general, i.e. non-market specific, term is obtained. This general idiosyncratic term is what one has in mind when referring to country-specific risk premium shocks. 
Knowledge of the magnitude of daily shocks attributable to international or country-specific sources may greatly assist the analysis of the impact of daily news. Although the method is purely statistical and in itself not appropriate for causal analysis, when paired with knowledge of actual news the application may provide valuable insights on how different types of shocks impact financial markets. For analysts, policy-makers and market participants who follow the developments of financial indicators on a regular and high-frequency (daily-weekly) basis, the cardinal question is not which macroeconomic or political factors have impacted indicators, because this is often obvious just by following the financial media. Rather, the main question is by how much the major news of the day of global, regional and country-specific origins have affected the indicators. The method applied here can address this issue. It can be an important tool to disentangle shocks on those days when seemingly important events happen both domestically and abroad. It can also be used to assess how shocks of different sources cumulated in financial market indicators, and so relatively how significant these were on longer horizons.

\subsection{Channels of risk propagation from the Euro zone periphery}

The final issue that this study briefly examines is how Euro zone periphery shocks have affected Central Eastern European (CEE) financial markets. The data set restricts analysis to two asset classes: $\mathrm{CDS}$ and equities. ${ }^{8}$ Correlations of three CEE country (Czech Republic, Hungary, and Poland) and three Euro zone periphery country (Ireland, Portugal, and Spain) indicators are investigated. In particular, it is examined which markets and which channels have been of more or of lesser importance in correlations between pairs of these countries. A relatively more important global factor as opposed to regional factors intuitively hints at a less direct link between indicators as changes of periphery indicators in this case coincide with shocks transmitted world-wide. In contrast, a larger regional factor correlation suggests that the risk is propagated to a smaller recipient group and is thus more direct. This application is therefore useful in gauging both how large and how direct the link has been between indicators.

$8 \quad$ FX rates are not worth analysing as Euro zone periphery countries do not have unique domestic currencies; whereas EMBI Global bond spreads are available for emerging markets only, thus there is no compilation for Euro zone periphery countries. CDS spread and equity index data were available for three periphery countries in the data set: Ireland, Portugal, and Spain. Greece has been omitted from the analysis due to lack of equity index data and lack of credible CDS spreads data in the run-up to default.

Acta Oeconomica 64 (2014) 
As described in Section 2.2, the products of Hungarian and periphery country loadings can be analysed to address the issue. The theoretical +1 value of loading products reflects a perfect positive correlation between the indicators of the two countries through the given factor and a value of -1 denotes perfect negative cor-
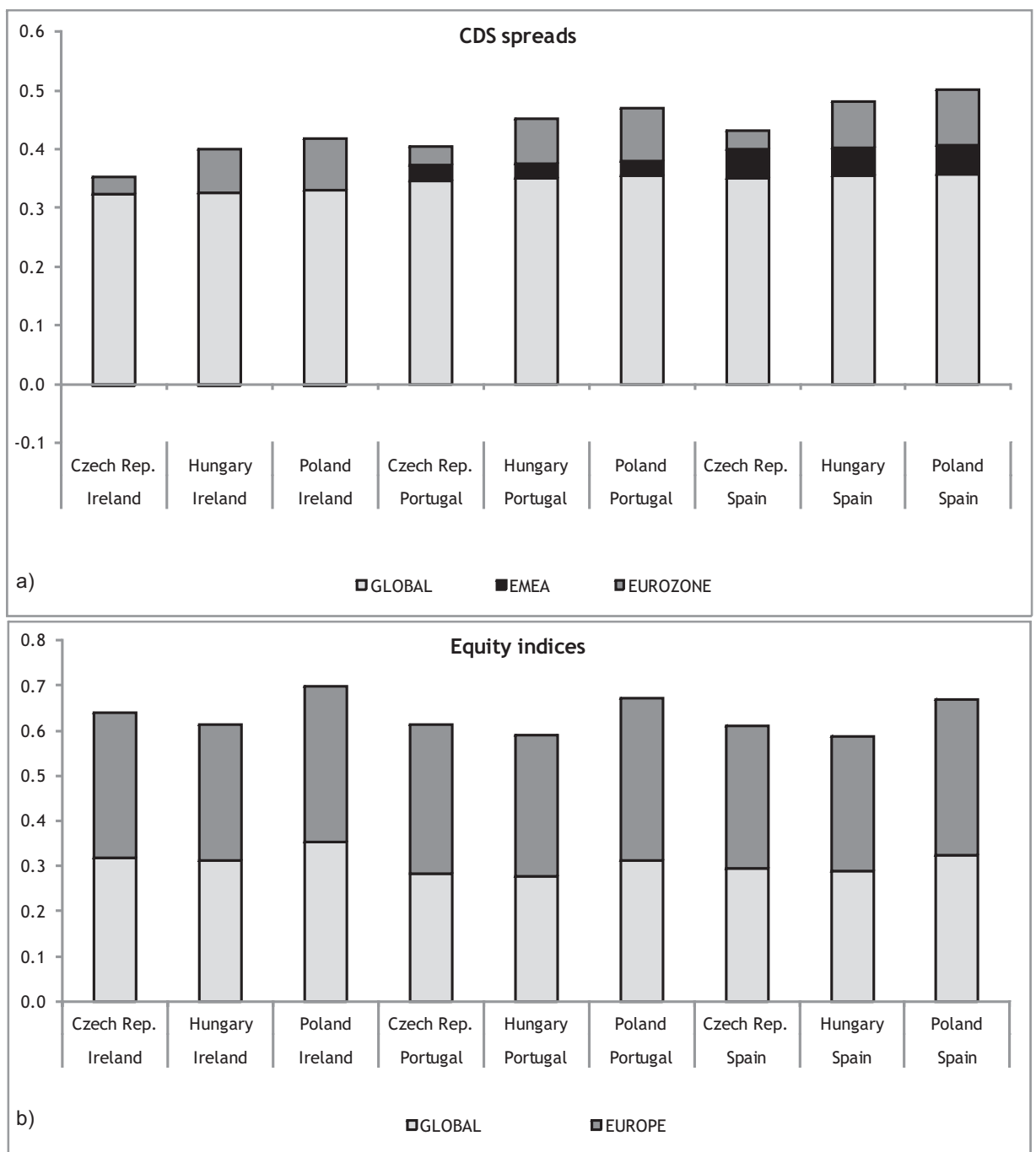

Figure 3. Channels of correlation (Panel a: CDS spreads, Panel b: Equity indices)

Notes: Correlation between indicators of two countries (a Euro zone periphery country and a Central Eastern European country) is segmented into components pertaining to factors of the model by taking the product of loadings of indicators on the given factors. The sums of these components do not necessarily sum to total bivariate correlations due to potential idiosyncratic term correlations and left out factors (Asia, Latin America). 
relation through the factor. Because each country has several factors plus the idiosyncratic term affecting its indicators, loadings will be less than 1 in absolute value, so the product terms will also be lower.

Figure 3 displays the results for CDS spreads and equity indices. Correlations between the indicators of the two regions are markedly different across the two asset classes. Overall correlations due to global and European regional factors are much higher in the case of equity indices (around 0.6-0.7) than CDS spreads (0.4-0.5), which suggests that interlinkages between the stock markets of the two regions are much stronger than those between sovereign credit spreads. Global factors in both asset classes account for loading products of roughly 0.3 in value, so that the difference is due to weaker regional correlation channels in the case of CDS spreads. In the case of equity indices, the European regional factor comprise nearly as large loading products as the global factor, whereas the two regional factors in the CDS market make up only a fraction of global correlation channels. The CDS spread link is thus not only smaller in magnitude, but proportionally it is also more impacted by the indirect global channel of risk propagation. Based on Fig-

ure 3 it is also evident that there are only smaller differences across countries, so the above statements are fairly robust to the particular selection of country pairs.

One notable shortcoming of the method used here to assess correlation channels is that these loading products are derived from a time-invariant factor structure of indicators for the full three-year period. They are, as a result, not able to account for shifts in the correlation structure, which may, however, be a crucial point to better understanding risk propagation from crisis countries. A dynamic analysis would require a different methodology, which lies beyond the scope of this paper and is left for future research.

\section{CONCLUSIONS}

This paper uses factor analysis with Procrustes rotation to analyse financial time series of a large cross-section of countries in both developed and emerging markets. Indicators are examined for four asset classes: CDS spreads account for sovereign credit derivatives, equity indices for stock markets, FX rates versus the USD for the currency market, and EMBI Global spreads for the FX bond market. The method allows a segmentation of indicators into global, regional, and idiosyncratic components.

The preliminary analysis of the data points out the importance of a global component in all examined markets, which supports a general finding of the literature. The extracted global components of nearly all markets show significant correlation with each other, in line with the risk-on/risk-off dichotomy in financial mar- 
kets observed since the crisis. In addition to the global factor, factor analysis points to the importance of further country groups in all markets studied. The finding of Kocsis - Nagy (2011) that country groups are formed mainly on a regional basis in CDS markets is supported for most other asset classes. Regional groups mainly follow a geographical pattern.

Variance decompositions indicate that global, regional, and country-specific components are all important in explaining financial indicator movements. Median variance shares of these factors are close to each other for various asset classes: global and country-specific components typically explain a third of the variance, while the factor of the region to which the indicator belongs explains around a fourth of total variances. Although there is considerable heterogeneity regarding individual country indicators, on the whole it appears that country-specific determinants are in most instances significant drivers of financial market indicators, suggesting potential scope for local policy-making to affect these indicators. Also, the significance of idiosyncratic factors indicates that the benefits of multi-country portfolios have still been significant in all asset classes, despite large indicator correlations in the post-financial crisis era.

A market monitoring application is straightforward to develop based on factor analysis results, which provides a method for the daily monitoring of market developments of any particular country's indicator. Such a monitoring tool identifies global, regional, and idiosyncratic components of the daily movements of the selected indicator. General risk premium shocks of global, regional, and country-specific origins, cleaned of market-specific noise, can also be recovered by using the information content of multiple asset classes. The method can greatly assist analysis of actual financial market developments because the separation of shocks attributable to international or domestic sources suggests the quantitative impact of international and domestic news items of the day.

Finally, the results of factor analysis were used to gauge which channels - global or regional - have been relatively more important in correlations between countries. In analysing correlation channels between Central Eastern European and Euro zone periphery countries, it is found that the global factor has been a relevant channel in both CDS spreads and equity indices. In the equity markets, however, the direct regional link has also been noteworthy, contrary to the CDS market. Thus, CEE equity indices have shown stronger and more direct co-movement with Euro zone periphery counterparts than CDS spreads and more of the co-movement has stemmed from the more direct regional channel. Nevertheless, it has to be emphasised that these results are general to the relatively long estimation sample and may conceal recent developments in the factor structure. It is left for future research to develop the model further into one that is also capable of incorporating the dynamics of factor structures. 


\section{REFERENCES}

Allen, F. - Gale, D. (2000): Financial Contagion. Journal of Political Economy, 108(1): 1-33.

Anderson, T.W. - Rubin, H. (1956): Statistical Inference in Factor Analysis. In: Neyman, J. (ed.): Proceedings of the Third Berkeley Symposium on Mathematical Statistics and Probability, 5: 111-150. Berkeley: University of California Press.

Beirne, J. - Caporale, G.M. - Shulze-Ghattas, M. - Spagnolo, N. (2009): Global and Regional Spillovers in Emerging Stock Markets: A Multivariate GARCH-in-Mean Analysis. CESifo Working Paper Series, 2794.

Broto, C. - Pérez-Quiros, G. (2011): Sovereign CDS Premia during the Crisis and Their Interpretation as a Measure of Risk. Banco de Espana Economic Bulletin, 2: 135-142.

Browne, M. (2001): An Overview of Analytic Rotation in Exploratory Factor Analysis. Multivariate Behavioral Research, 36(1): 111-150.

Collin-Dufresne, P. - Goldstein, R.S. - Martin, J.S. (2001): The Determinants of Credit Spread Changes. The Journal of Finance, 56(6): 2177-2207.

Corsetti, G. - Pericoli, M. - Sbracia, M. (2005): Some Contagion, Some Interdependence: More Pitfalls in Tests of Financial Contagion. Journal of International Money and Finance, 24(8): $1177-1199$.

Dasgupta, A. - Leon-Gonzales, R. - Shortland, A. (2010): Regionality Revisited: An Examination of the Direction of Spread of Currency Crises. DIW Discussion Papers, 1023.

Diebold, F.X. - Nerlove, M. (1989): The Dynamics of Exchange Rate Volatility: A Multivariate Latent Factor Arch Model. Journal of Applied Econometrics, 4(1): 1-21.

Dungey, M. - Martin, V.L. (2007): Unravelling Financial Market Linkages during Crises. Journal of Applied Econometrics, 22: 89-119.

Ehrmann, M. - Fratscher, M. - Rigobon, R. (2005): Stocks, Bonds, Money Markets and Exchange Rates: Measuring International Financial Transmission. NBER Working Papers, 11166.

Francis, N. - Owyanh, M.T. - Savascin, Ö. (2012): An Endogeneously Clustered Factor Approach to International Business Cycles. Federal Reserve Bank of St. Louis Working Paper, 2012-014A.

Forbes, K.J. - Chinn, M.D. (2003): A Decomposition of Global Linkages in Financial Markets over Time. NBER Working Papers, 9555.

Grice, J.W. (2001): Computing and Evaluating Factor Scores. Psychological Methods, 6: 430-450.

Kim, D.H. - Loretan, M. - Remonola, E.M. (2009): Contagion and Risk Premia in the Amplification of Crisis: Evidence from Asian Names in the Global CDS Market. Journal of Asian Economics, 21(3): 314-326.

King, M. - Sentana, E. - Whadwani, S. (1990): Volatility and Links between National Stock Markets. NBER Working Papers, 3357.

Kocsis, Z. - Nagy, D. (2011): Variance Decomposition of CDS Spreads. MNB Bulletin, 3: 36-50.

Kose, M.A. - Otrok, C. - Whiteman, C.H. (2003): International Business Cycles: World, Region, and Country-Specific Factors. American Economic Review, 93(4): 1216-1239.

Longstaff, F.A. - Pan, J. - Pedersen, L.H. - Singleton, K.J. (2011): How Sovereign is Sovereign Credit Risk? American Economic Journal: Macroeconomics, 3(2): 75-103.

McCrae, R.R. - Zonderman, A.B. - Costa, P.T. - Bond, M.H. - Paunonen, S.V. (1996): Evaluating Replicability of Factors in the Revised NEO Personality Inventory: Confirmatory Factor Analysis versus Procrustes Rotation. Journal of Personality and Social Psychology, 4: 681-691.

Lorenzo-Seva, U. - ten Berge, J.M.F. (2006): Tucker's Congruence Coefficient as a Meaningful Index of Factor Similarity. Methodology, 2(2): 57-64.

McGuire, P. - Schrijvers, M.A. (2003): Common Factors in Emerging Market Spreads. BIS Quarterly Review, 4: 65-78. 


\title{
APPENDIX
}

\author{
Table A1
}

Data set: Time sample and country cross-sections

\begin{tabular}{|c|c|c|}
\hline \multicolumn{3}{|l|}{ INDICATOR } \\
\hline \multirow[t]{8}{*}{ CDS spreads } & Estimation Period & 1 May 2009-31 Aug 2011 \\
\hline & GLOBAL & 35 countries \\
\hline & EMEA & Hungary, Poland, Czech Republic, Slovakia, \\
\hline & & Romania, Croatia, Bulgaria, Lithuania, Estonia, \\
\hline & & Ukraine, Russia, Turkey, South Africa, Kazakhstan \\
\hline & EURO ZONE & $\begin{array}{l}\text { Austria, France, Belgium, Netherlands, Spain, } \\
\text { Portugal, Ireland, Italy }\end{array}$ \\
\hline & LATIN AMERICA & $\begin{array}{l}\text { Mexico, Brazil, Argentina, Peru, Venezuela, Chile, } \\
\text { Colombia }\end{array}$ \\
\hline & ASIA & $\begin{array}{l}\text { China, Thailand, Malaysia, Indonesia, Vietnam, } \\
\text { South Korea }\end{array}$ \\
\hline \multirow[t]{9}{*}{ Equity indices } & Estimation Period & 13 Aug 2009 - 31 Jan 2012 \\
\hline & GLOBAL & 32 countries \\
\hline & EUROPE & Hungary, Poland, Czech Republic, Romania, Russia, \\
\hline & & Turkey, South Africa, Israel, Ireland, Portugal, \\
\hline & & Spain, Austria, Netherlands, Sweden, Germany, \\
\hline & & France, United Kingdom, Switzerland \\
\hline & ASIA & India, Thailand, China, Indonesia, Hong Kong, \\
\hline & & Philippines, Australia, New Zealand, Japan \\
\hline & AMERICA & Mexico, Brazil, Argentina, Chile, United States \\
\hline \multirow[t]{6}{*}{ FX rates } & Estimation Period & 7 July $2009-8$ Sept 2011 \\
\hline & GLOBAL & 18 countries \\
\hline & EUROPE & Hungary, Poland, Czech Republic, Romania, \\
\hline & & Croatia, Eurozone, United Kingdom \\
\hline & EMERGING ASIA & Malaysia, Indonesia, South Korea, Philippines \\
\hline & OTHER & $\begin{array}{l}\text { Russia, Turkey, South Africa, Mexico, Australia, } \\
\text { New Zealand, Canada }\end{array}$ \\
\hline \multirow{4}{*}{$\begin{array}{l}\text { EMBI Global } \\
\text { spreads }\end{array}$} & Estimation Period & 1 July 2009 - 4 Aug 2011 \\
\hline & GLOBAL & 25 countries \\
\hline & EMEA & $\begin{array}{l}\text { Hungary, Poland, Bulgaria, Serbia, Ukraine, Russia, } \\
\text { Turkey, South Africa, Kazakhstan, Lebanon, Iraq, } \\
\text { Ghana, Gabon }\end{array}$ \\
\hline & LATIN AMERICA & $\begin{array}{l}\text { Mexico, Brazil, Argentina, Chile, Peru, Colombia, } \\
\text { Panama, Venezuela, Uruguay, Dominican Republic, } \\
\text { Jamaica, El Salvador }\end{array}$ \\
\hline
\end{tabular}

Source: Data are daily changes of last price quotes from Bloomberg in the case of all series except for the JP Morgan EMBI Global spreads, which are sourced from Datastream. Percentage changes are used in the case of equities and FX rates, while basis point changes are used for CDS spreads and EMBI spreads.

Notes: Countries are listed in the regional classification that was used in priors for the Procrustes rotation. The regional classification of countries was derived from an exploratory factor analysis of the data using varimax rotation. (These are available from the author upon request). 
Table A2

Number of factors proposed by various standard statistical criteria and the number of factors chosen in the Procrustes priors

\begin{tabular}{lccccc}
\hline & $\begin{array}{c}\text { Minimum } \\
\text { eigenvalue of 1 }\end{array}$ & $\begin{array}{c}\text { Cumulated } \\
\text { explained } \\
\text { variance } \\
>60 \%\end{array}$ & $\begin{array}{c}\text { Minimum } \\
\text { average } \\
\text { partial }\end{array}$ & Scree plot & $\begin{array}{c}\text { Chosen factor } \\
\text { number }\end{array}$ \\
\hline CDS spreads & 5 & 3 & 6 & 6 & 5: global + 4 regional \\
Equity indices & 3 & 3 & 3 & 4 & 4 : global + 3 regional \\
FX rates vs USD & 3 & 2 & 3 & 4 & 4: global + 3 regional \\
EMBI Global spreads & 3 & 2 & 3 & 5 & 3: global + 2 regional \\
\hline
\end{tabular}

Table A3

Factor structure (loadings matrix after Procrustes rotation)

A3.1. CDS spreads

\begin{tabular}{lrrrrr}
\hline & GLOBAL & EMEA & ASIA & $\begin{array}{r}\text { LATIN } \\
\text { AMERICA }\end{array}$ & EURO ZONE \\
\hline Hungary & 0.657 & 0.457 & -0.109 & 0.045 & 0.122 \\
Poland & 0.664 & 0.466 & 0.003 & 0.084 & 0.144 \\
Czech Republic & 0.650 & 0.479 & 0.053 & 0.073 & 0.050 \\
Slovakia & 0.541 & 0.483 & 0.030 & 0.013 & 0.027 \\
Romania & 0.779 & 0.494 & -0.141 & -0.122 & -0.037 \\
Croatia & 0.758 & 0.486 & -0.103 & -0.026 & 0.006 \\
Bulgaria & 0.787 & 0.469 & -0.066 & -0.037 & -0.035 \\
Lithuania & 0.549 & 0.324 & 0.053 & -0.069 & -0.031 \\
Estonia & 0.496 & 0.270 & 0.015 & -0.039 & -0.107 \\
Ukraine & 0.355 & 0.362 & 0.039 & 0.102 & 0.011 \\
Russia & 0.656 & 0.588 & 0.236 & 0.258 & 0.113 \\
Turkey & 0.654 & 0.574 & 0.186 & 0.284 & 0.169 \\
South Africa & 0.635 & 0.602 & 0.225 & 0.224 & 0.123 \\
Kazakhstan & 0.636 & 0.501 & 0.210 & 0.172 & 0.110 \\
China & 0.678 & 0.045 & 0.566 & 0.017 & -0.105 \\
Thailand & 0.585 & 0.087 & 0.531 & -0.013 & 0.022 \\
Malaysia & 0.620 & 0.095 & 0.608 & -0.037 & -0.074 \\
Indonesia & 0.617 & 0.161 & 0.569 & 0.003 & -0.113 \\
Vietnam & 0.517 & 0.132 & 0.478 & 0.016 & -0.010 \\
South Korea & 0.678 & 0.112 & 0.621 & 0.045 & -0.063 \\
Mexico & 0.703 & 0.127 & -0.038 & 0.636 & -0.068 \\
Brazil & 0.721 & 0.123 & -0.052 & 0.641 & -0.042 \\
\hline
\end{tabular}


Table A3.1. (cont.)

\begin{tabular}{lcrrrr}
\hline & GLOBAL & EMEA & ASIA & $\begin{array}{r}\text { LATIN } \\
\text { AMERICA }\end{array}$ & EURO ZONE \\
\hline Argentina & 0.528 & 0.207 & 0.087 & 0.367 & 0.012 \\
Peru & 0.634 & 0.108 & -0.047 & 0.558 & -0.057 \\
Venezuela & 0.474 & 0.113 & 0.061 & 0.306 & -0.006 \\
Chile & 0.393 & 0.131 & 0.034 & 0.272 & -0.017 \\
Colombia & 0.721 & 0.154 & -0.012 & 0.634 & -0.056 \\
Spain & 0.539 & 0.104 & -0.021 & -0.037 & 0.652 \\
Portugal & 0.533 & 0.053 & -0.025 & -0.016 & 0.633 \\
Ireland & 0.496 & -0.005 & -0.052 & -0.071 & 0.609 \\
Italy & 0.603 & 0.125 & 0.008 & -0.063 & 0.647 \\
Austria & 0.620 & 0.204 & -0.086 & -0.015 & 0.364 \\
France & 0.577 & 0.020 & -0.101 & -0.012 & 0.461 \\
Belgium & 0.550 & 0.047 & -0.099 & -0.031 & 0.618 \\
Netherlands & 0.598 & 0.119 & 0.032 & 0.010 & 0.443 \\
\hline
\end{tabular}

Notes: For visualisation purposes, values between 0.3 and 0.7 are lightly, values between 0.7 and 1 are darkly shaded. 
A3.2. Equity indices

\begin{tabular}{|c|c|c|c|c|}
\hline & GLOBAL & EUROPE & ASIA & AMERICA \\
\hline Hungary & 0.448 & 0.576 & 0.128 & 0.104 \\
\hline Poland & 0.503 & 0.664 & 0.152 & 0.154 \\
\hline Czech Republic & 0.455 & 0.615 & 0.259 & 0.005 \\
\hline Romania & 0.415 & 0.432 & 0.321 & -0.048 \\
\hline Russia & 0.522 & 0.548 & 0.255 & 0.168 \\
\hline Turkey & 0.386 & 0.515 & 0.091 & 0.077 \\
\hline South Africa & 0.584 & 0.508 & 0.169 & 0.132 \\
\hline Israel & 0.441 & 0.427 & 0.038 & 0.104 \\
\hline Mexico & 0.588 & 0.184 & -0.116 & 0.558 \\
\hline Brazil & 0.569 & 0.176 & -0.086 & 0.587 \\
\hline Argentina & 0.640 & 0.197 & -0.103 & 0.478 \\
\hline Chile & 0.546 & 0.241 & 0.066 & 0.316 \\
\hline India & 0.462 & 0.246 & 0.342 & 0.085 \\
\hline Thailand & 0.416 & 0.128 & 0.388 & 0.030 \\
\hline China & 0.352 & -0.040 & 0.335 & 0.009 \\
\hline Indonesia & 0.476 & 0.113 & 0.479 & -0.017 \\
\hline Hong Kong & 0.601 & 0.040 & 0.589 & -0.016 \\
\hline Philippines & 0.222 & -0.012 & 0.450 & -0.089 \\
\hline Australia & 0.620 & -0.033 & 0.577 & -0.115 \\
\hline New Zealand & 0.363 & 0.039 & 0.438 & -0.213 \\
\hline Ireland & 0.646 & 0.517 & -0.044 & 0.042 \\
\hline Portugal & 0.620 & 0.540 & -0.079 & 0.025 \\
\hline Spain & 0.700 & 0.521 & -0.207 & -0.018 \\
\hline Austria & 0.661 & 0.564 & 0.028 & 0.051 \\
\hline Netherlands & 0.796 & 0.536 & -0.128 & 0.024 \\
\hline Sweden & 0.709 & 0.522 & -0.073 & 0.099 \\
\hline Germany & 0.769 & 0.521 & -0.176 & 0.051 \\
\hline France & 0.822 & 0.521 & -0.183 & -0.021 \\
\hline United Kingdom & 0.763 & 0.504 & -0.086 & 0.066 \\
\hline Switzerland & 0.721 & 0.485 & -0.079 & 0.044 \\
\hline Japan & 0.504 & -0.094 & 0.507 & -0.150 \\
\hline United States & 0.650 & 0.260 & -0.237 & 0.472 \\
\hline
\end{tabular}

Notes: For visualisation purposes, values between 0.3 and 0.7 are lightly, values between 0.7 and 1 are darkly shaded. 
A3.3. FX Rates versus the USD

\begin{tabular}{|c|c|c|c|c|}
\hline & GLOBAL & EUROPE & EMERGING ASIA & OTHER \\
\hline Hungary & 0.784 & 0.470 & -0.116 & 0.154 \\
\hline Poland & 0.831 & 0.410 & -0.142 & 0.177 \\
\hline Czech Republic & 0.681 & 0.607 & -0.100 & 0.136 \\
\hline Romania & 0.658 & 0.672 & -0.024 & 0.094 \\
\hline Croatia & 0.560 & 0.771 & -0.008 & 0.105 \\
\hline Russia & 0.619 & 0.250 & 0.185 & 0.142 \\
\hline Turkey & 0.752 & 0.161 & -0.090 & 0.287 \\
\hline South Africa & 0.683 & 0.160 & -0.022 & 0.371 \\
\hline Mexico & 0.650 & 0.073 & -0.151 & 0.404 \\
\hline Malaysia & 0.507 & -0.121 & 0.701 & -0.029 \\
\hline Indonesia & 0.420 & -0.115 & 0.571 & -0.072 \\
\hline South Korea & 0.505 & -0.013 & 0.533 & 0.091 \\
\hline Philippines & 0.429 & -0.026 & 0.365 & -0.025 \\
\hline Australia & 0.622 & 0.271 & 0.151 & 0.679 \\
\hline New Zealand & 0.570 & 0.304 & 0.127 & 0.589 \\
\hline Eurozone & 0.589 & 0.791 & -0.038 & 0.105 \\
\hline United Kingdom & 0.509 & 0.396 & -0.032 & 0.226 \\
\hline Canada & 0.636 & 0.170 & -0.051 & 0.478 \\
\hline
\end{tabular}

Notes: For visualisation purposes, values between 0.3 and 0.7 are lightly, values between 0.7 and 1 are darkly shaded. 
A3.4. EMBI Global spreads

\begin{tabular}{l|c|c|c}
\hline & GLOBAL & LATIN AMERICA & EMEA \\
\hline Hungary & 0.550 & 0.026 & 0.253 \\
Poland & 0.562 & -0.048 & 0.212 \\
\hline Bulgaria & 0.557 & 0.151 & 0.534 \\
\hline Serbia & 0.664 & 0.127 & 0.461 \\
Ukraine & 0.372 & 0.147 & 0.461 \\
\hline Russia & 0.658 & 0.382 & 0.571 \\
Turkey & 0.715 & 0.421 & 0.390 \\
South Africa & 0.724 & 0.266 & 0.436 \\
Kazakhstan & 0.522 & 0.193 & 0.622 \\
\hline Lebanon & 0.700 & 0.167 & 0.277 \\
Iraq & 0.667 & 0.187 & 0.443 \\
Ghana & 0.599 & 0.090 & 0.525 \\
Gabon & 0.643 & 0.100 & 0.537 \\
\hline Mexico & 0.612 & 0.662 & 0.186 \\
Brazil & 0.685 & 0.654 & 0.204 \\
\hline Argentina & 0.493 & 0.503 & 0.352 \\
\hline Chile & 0.431 & 0.209 & 0.066 \\
Peru & 0.675 & 0.614 & 0.119 \\
Colombia & 0.595 & 0.685 & 0.209 \\
Panama & 0.796 & 0.506 & 0.119 \\
Venezuela & 0.404 & 0.320 & 0.401 \\
\hline Uruguay & 0.835 & 0.403 & 0.109 \\
Dominican Republic & 0.552 & 0.103 & 0.271 \\
\hline Jamaica & 0.497 & 0.185 & 0.105 \\
\hline El Salvador & 0.829 & 0.351 & \\
\hline & & & \\
\hline
\end{tabular}

Notes: For visualisation purposes values between 0.3 and 0.7 are lightly, values between 0.7 and 1 are darkly shaded. 


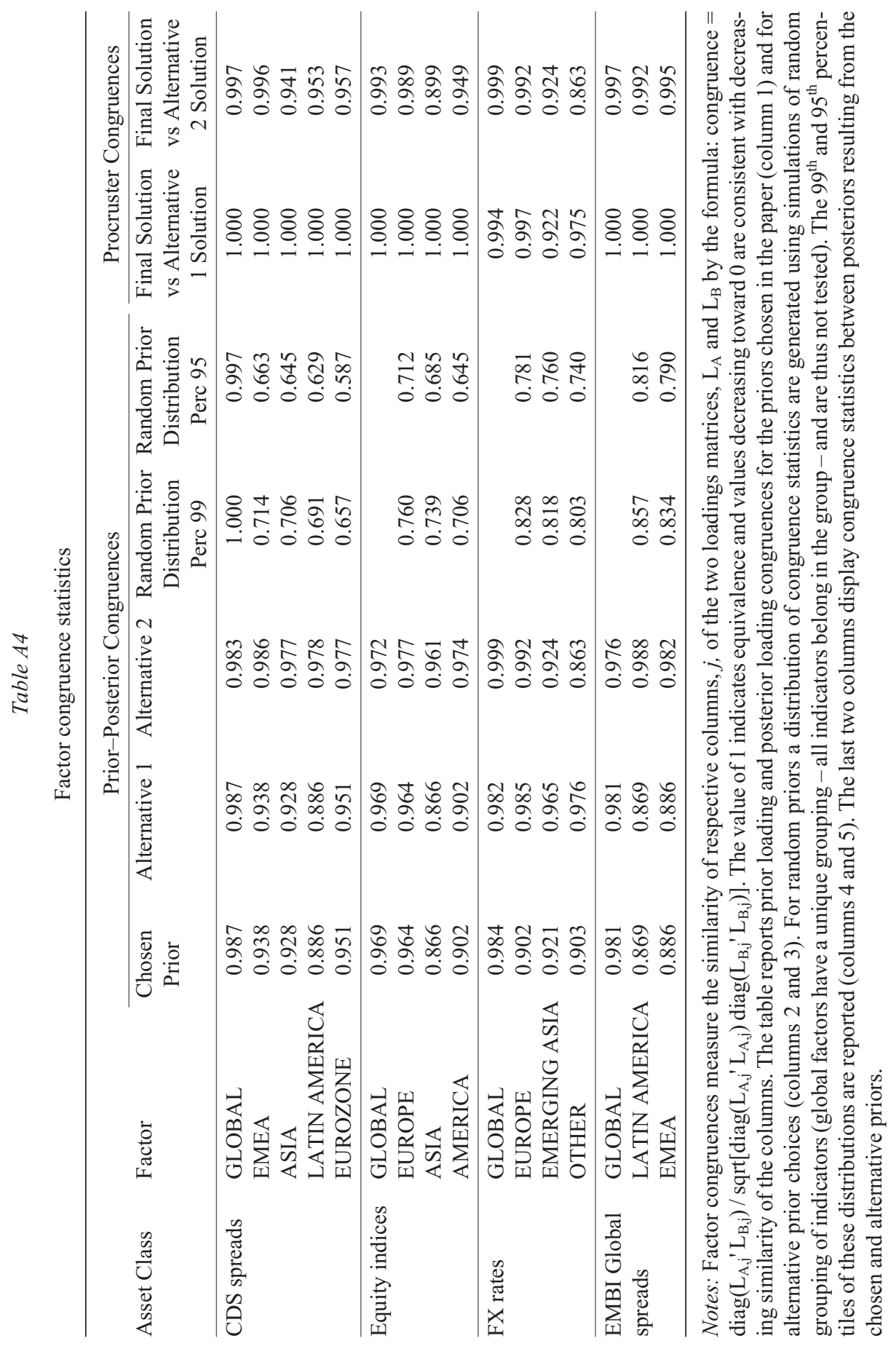

Acta Oeconomica 64 (2014) 


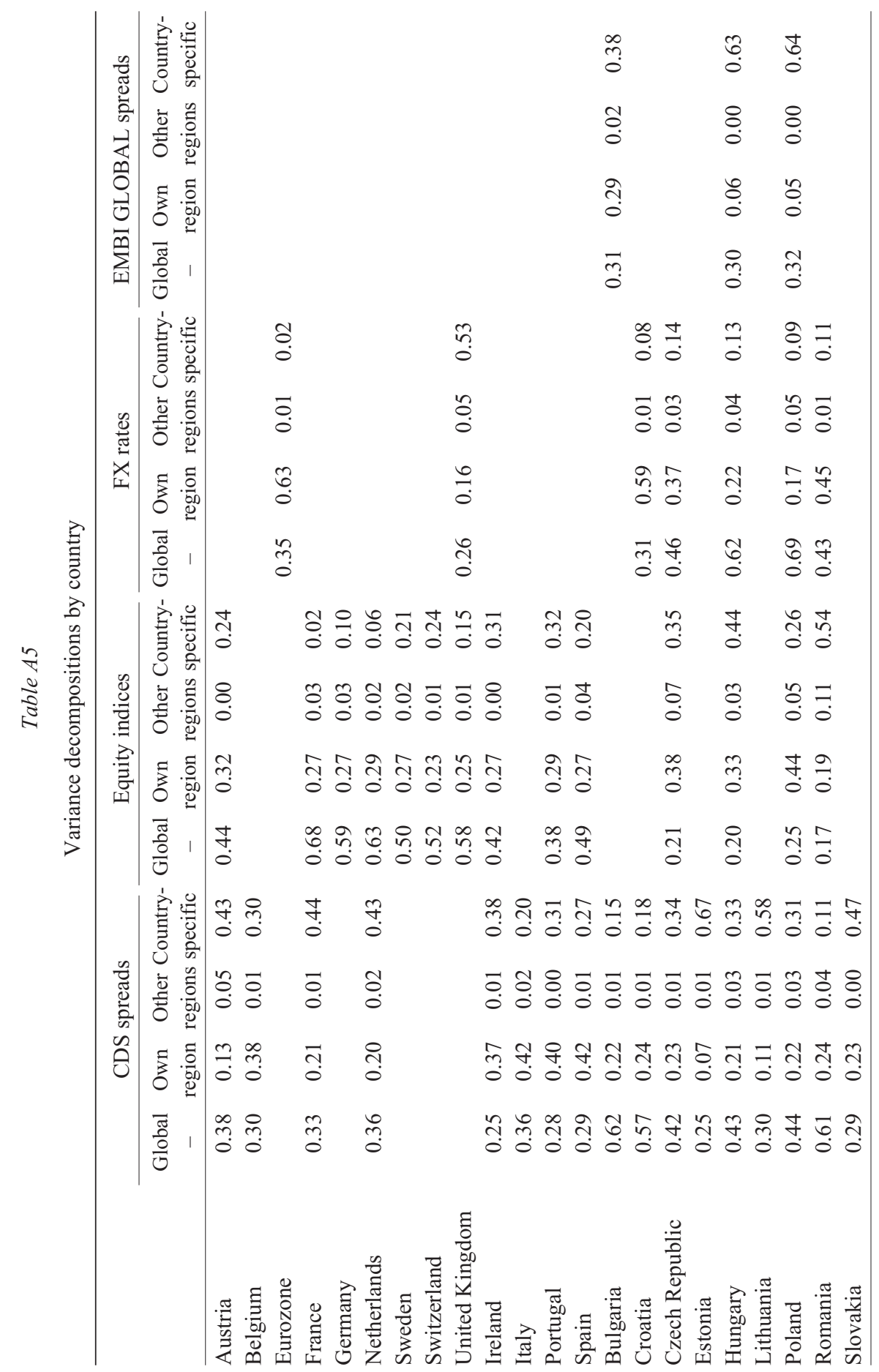




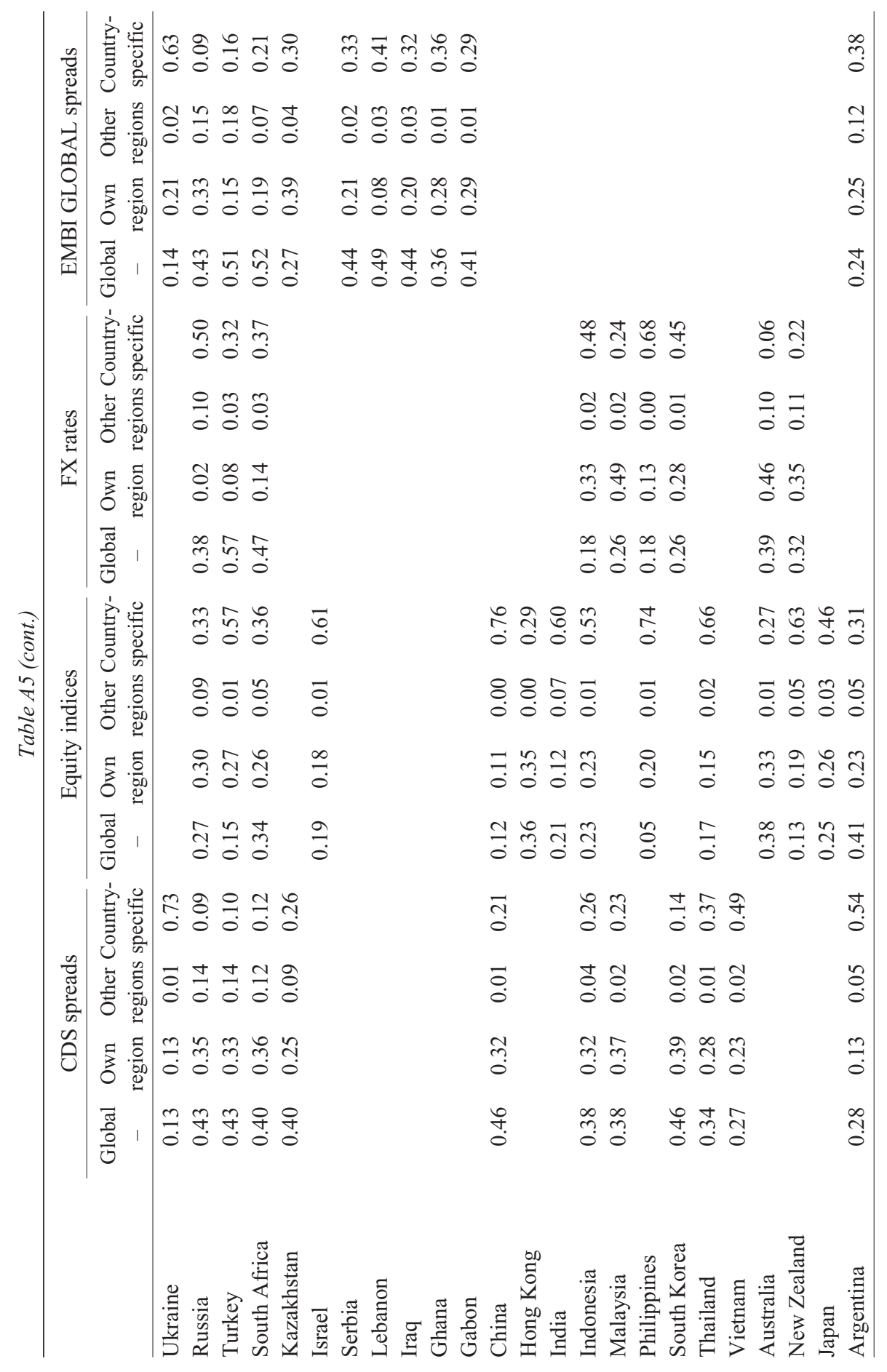




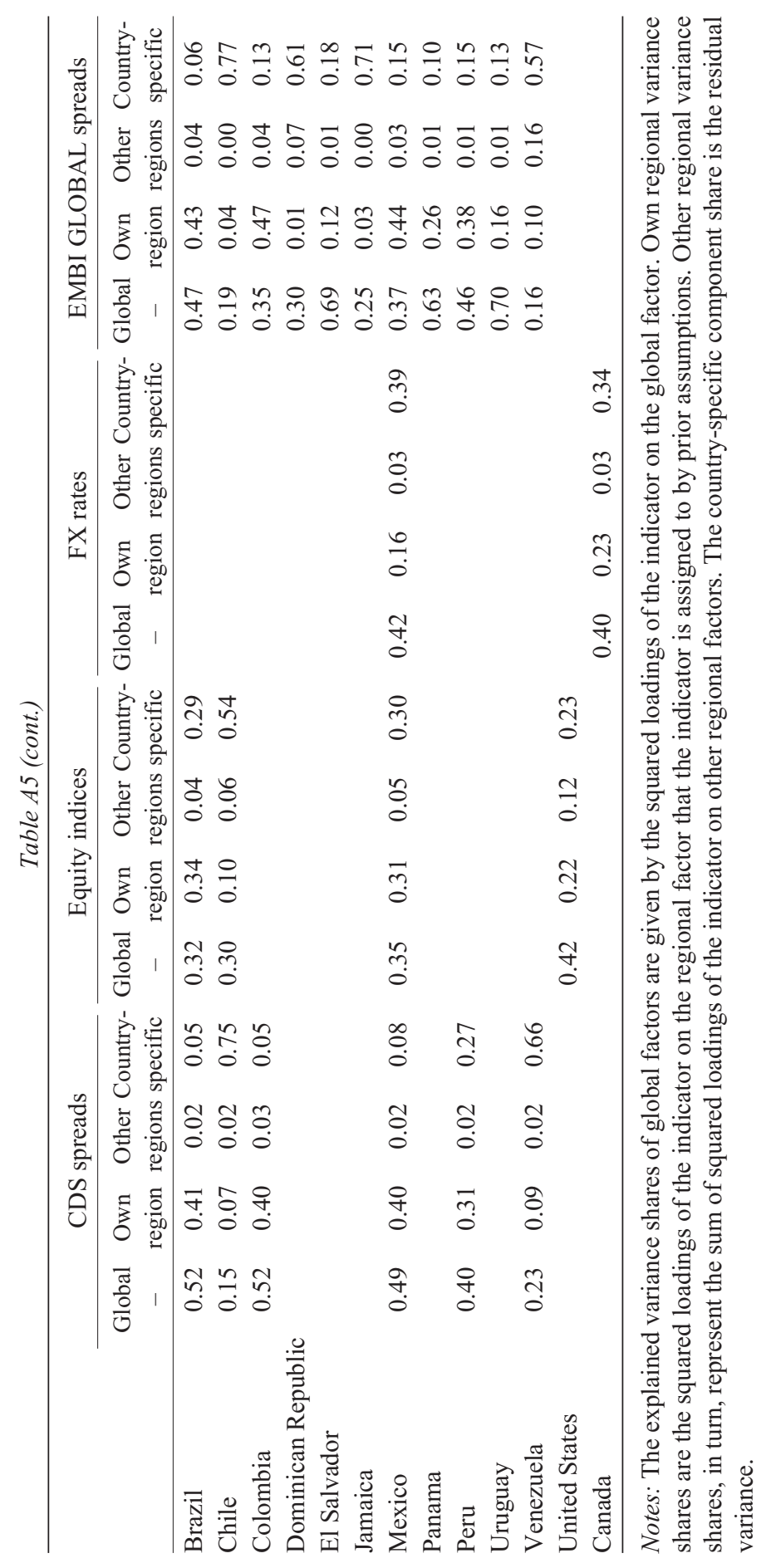

